\title{
Spatial Soil Modeling of Organochlorine Pesticides, Their Pools and Volatilization Fluxes
}

\author{
Klára Komprdová ${ }^{1}$, Jiří Komprda ${ }^{1}$, Milan Sáňka ${ }^{1}$, and Ondřej Hájek ${ }^{2}$ \\ ${ }^{1}$ RECETOX (Research Centre for Toxic Compounds in the Environment), Kamenice 126/3, \\ CZ-625 00 Brno, Czech Republic \\ ${ }^{2}$ Department of Botany and Zoology, Masaryk University, Kotlářská 2, \\ CZ-611 37 Brno, Czech Republic \\ komprdova@recetox.muni.cz
}

\begin{abstract}
The goal of this study was to use the modeling tools for prediction of environmental concentrations and pools of pesticides (HCB and DDT) in soil. The characterization and quantification of secondary background sources of $\mathrm{HCB}$, were computed using fugacity based deterministic model. Areas with a high potential for deposition and volatilization of HCB were identified. Results of modeling were maps showing spatial distribution of HCB and DDT in the Czech Republic which have been visualized on the web portal GENASIS (Global Environmental Assessment Information System) to provide information on environment contamination.
\end{abstract}

Keywords: pesticides, pool, modeling, fugacity, POPs.

\section{Introduction}

HCB and DDT were produced during last decades for various agricultural and industrial purposes. They are widely distributed in all environmental compartments including air, soil, water, sediment and biota because of their physical-chemical properties. The considerable amount of these compounds is still presented mainly in the soil. Sources of HCB in the environment in the mid 1990s were considered to be the manufacture of chlorinated solvents, the manufacture and application of $\mathrm{HCB}$ containing pesticides [1], metal production and the residential sector [2]. DDT was widely used in the second half of the 20th century and Czechoslovakia was an important producer and consumer of DDT [3].

In addition to the long-range transport, HCB and DDT are also re-mobilized from primary and secondary sources such as contaminated sites and soils, which may strongly influence their concentration in air on shorter spatial scales e.g., in areas of former heavy HCB application elevated soil concentrations of HCB are commonly found [4]. DDT is very persistent in soil, too.

One of important properties of those compounds is semivolatility. When atmospheric concentrations of POPs (persistent organic pollutants) declined as a 
result of restrictions to low level volatilization from soil become their significant or even dominant emission source in the environment. Spatially resolved deterministic model based on fugacity approach was created for calculation of volatilization fluxes and total amount of HCB being volatilized was predicted. Influence of environmental temperature changes and variation of organic carbon content in soil was included in the model.

\subsection{Data Sources}

In central Europe, unique continuous monitoring of POPs is conducted at the background sampling site Košetice, Czech Republic, since 1988. This dataset allow analyzing pollution level and temporal trend in various environmental matrices and study the environmental fate of POPs more deeply. Input concentrations for the soil model were collected from several projects. The most important sources of data came from two nation-wide soil monitoring systems: Basal monitoring of agricultural soils conducted by CISTA (Central Institute for Supervising and Testing in Agriculture) and Basal monitoring of soils in protected areas conducted by ANLP (Agency for Nature and Landscape Protection). Other data sources were projects conducted by RECETOX (Research Centre for Toxic Compounds in the Environment) for various purposes and at various spatial scales. Altogether, comprehensive data from about 600 sites around the country formed the basic database used for further evaluation and modeling. The collected data covered not only soil concentrations of POPs but also other important parameters measured at individual sites, e.g. geographical coordinates, soil organic carbon content, soil type, land use.

\section{Methodology}

\subsection{Determination of the Spatial and Quantitative Distribution of POPs in Soil}

Concentration maps for each substance in soil at a $1 \times 1 \mathrm{~km}$ grid resolution were constructed using the GIS approach. The prediction model was based on the dependency of POP concentration levels on environmental parameters. Only parameters which were supposed to influence the concentration were used. Four groups of predictor variables were used: 1 . markers of anthropogenic activity such as distance from industry, distance from populated areas and road classes, $\mathrm{NO}_{\mathrm{x}}, \mathrm{SO}_{2}$, particulate matter content in air, old dumps, size of populated area 2. climatic factors such as altitude, mean annual temperature, annual precipitation 3 . soil properties such as soil type, character of soil and organic carbon content and 4. land cover [5]. Prior to modeling, a square grid was generated for the Czech Republic using ArcGIS 9.2 (in total 80033 squares of $1 \times 1 \mathrm{~km})$.

Non-parametric methods, CART [6] and Random Forest [7], were used for the prediction of POP soil concentrations in $\mathrm{CZ}$. The reason is the character of data 
(categorial variables with many categories, assumption of nonlinear relationships, non-normal distribution of variables and multicolinearity). The concentrations' maps of HCB and DDT were used from previous study on RECETOX [8]. A pool of POPs in the top soil layer was calculated for each cell of the grid using concentration of pesticides and a bulk density and thickness of soil horizons. The values were specific for each grid square [9].

\subsection{Construction of a Fugacity Model for Determining the Volatilization of POPs from Czech Soils}

Land cover, soil type, temperature gradient and organic carbon content in soil form the basis of the applied fugacity model. It was necessary to construct temperature maps for the whole area of the Czech Republic. Results were evaluated according to the potential of individual areas to volatilization and deposition of HCB. The fugacity model [10] was based on a dynamic box model, based on previous experience with the construction and use of a similar model type comprising both soil and air [11]. Input parameters were both physical-chemical properties of the studied substances and properties of the environment, e.g. temperature and organic carbon content in soil. Three resistance concept based on fugacity approach was used (Fig. 1).

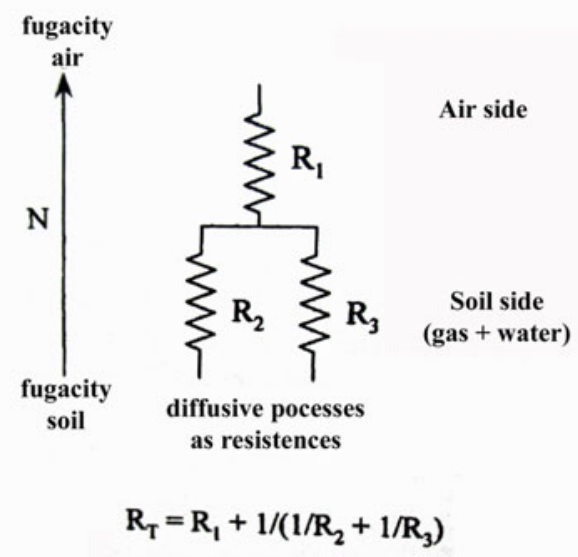

Fig. 1. Three resistance concept based on fugacity approach [10]

Volatilization flux is proportional to difference of fugacities between air and soil. Fugacity as criterion of equilibrium is a "pressure" of POPs in compartments. The model contains mass transfer coefficients describing transfer over the air-soil interphase (air and soil compartments are homogenous boxes). Temperature dependence was included through partitioning coefficients $\left(\mathrm{K}_{\mathrm{ow}} \mathrm{n}\right.$-octanol/water, $\mathrm{K}_{\mathrm{aw}}$ air/water, $\mathrm{K}_{\mathrm{oc}}$ organic carbon/water, $\mathrm{K}_{\mathrm{sw}}$ soil/water). 
Correction of partitioning coefficients to the specific environmental temperature (van't Hoff's equation):

$$
\mathrm{K}_{\mathrm{aw}}=\mathrm{K}_{\mathrm{aw} 0} * \mathrm{e}^{(\mathrm{dH} / \mathrm{R} *(1 / \mathrm{T} 0-1 / \mathrm{T}))}
$$

Evaluation of partitioning coefficients soil-water $\left(\mathrm{K}_{\mathrm{sw}}\right)$ :

$$
\begin{gathered}
\mathrm{K}_{\mathrm{oc}}=\mathrm{K}_{\mathrm{ow}} * 0.41 \\
\mathrm{~K}_{\mathrm{sw}}^{{ }_{\mathrm{sw}}}=\mathrm{K}_{\mathrm{oc}} * f_{\mathrm{oc}} \\
\mathrm{K}_{\mathrm{sw}}=\mathrm{K}^{\prime}{ }_{\mathrm{sw}} /(1000 * \rho)
\end{gathered}
$$

Evaluation of fugacity capacities $\mathrm{Z}\left[\mathrm{mol} \cdot\left(\mathrm{m}^{3} \cdot \mathrm{Pa}\right)^{-1}\right]$ :

$$
\begin{gathered}
\mathrm{Z}_{\mathrm{a}}=1 /(\mathrm{R} * \mathrm{~T}) \\
\mathrm{Z}_{\mathrm{l}}=1 /\left(\mathrm{K}_{\mathrm{awt}} * \mathrm{R} * \mathrm{~T}\right) \\
\mathrm{Z}_{\mathrm{s}}=\mathrm{K}_{\mathrm{sw}} * \mathrm{Z}_{\mathrm{l}} \\
\mathrm{Z}_{\text {sbulk }}=f_{\mathrm{s}} * \mathrm{Z}_{\mathrm{s}}+f_{\mathrm{a}} * \mathrm{Z}_{\mathrm{a}}+f_{\mathrm{l}} * \mathrm{Z}_{\mathrm{l}}
\end{gathered}
$$

Evaluation of transport coefficients D [mol $\left.\cdot(\mathrm{h} \cdot \mathrm{Pa})^{-1}\right]$ :

$$
\begin{gathered}
\mathrm{D}_{\mathrm{a}}=\mathrm{MTC}_{\mathrm{a}} * \mathrm{Z}_{\mathrm{a}} \\
\mathrm{D}_{\mathrm{sa}}=\mathrm{MTC}_{\mathrm{sa}} * \mathrm{Z}_{\mathrm{a}} \\
\mathrm{D}_{\mathrm{sl}}=\mathrm{MTC}_{\mathrm{sw}} * \mathrm{Z}_{\mathrm{l}} \\
\mathrm{D}_{\mathrm{s}}=1 /\left(1 / \mathrm{D}_{\mathrm{a}}+1 /\left(\mathrm{D}_{\mathrm{sa}}+\mathrm{D}_{\mathrm{sl}}\right)\right)
\end{gathered}
$$

Evaluation of total flux of pollutant between air and soil:

$$
\begin{gathered}
\mathrm{F}=\mathrm{F}_{\mathrm{sa}}-\mathrm{F}_{\mathrm{as}} \\
\mathrm{F}=\mathrm{D}_{\mathrm{s}} * \mathrm{f}_{\mathrm{s}}-\mathrm{D}_{\mathrm{s}} * \mathrm{f}_{\mathrm{a}}
\end{gathered}
$$

When s-soil, a-air, l-liquid, w-water, R- gas constant $8.314\left[\mathrm{~J} \cdot(\mathrm{mol} \cdot \mathrm{K})^{-1}\right]$, MTCmass transport coefficient $\left[\mathrm{m} \cdot \mathrm{h}^{-1}\right], f_{s}, f_{a}, f_{l}$ - solid, liquid and air fractions in soil, $\mathrm{f}_{\mathrm{s}}, \mathrm{f}_{\mathrm{a}}$ - fugacities of pollutant in soil and air [Pa], F- flux of pollutant over air/soil interphase $\left[\mathrm{mol} \cdot \mathrm{h}^{-1}\right], \mathrm{f}_{\mathrm{a}}$ - fugacity of pollutant in air was set to average fugacity from regular monitoring in Kosetice., $\mathrm{f}_{\mathrm{s}}$ - fugacity of pollutant in soil was calculated from predicted concentration maps using $\mathrm{Z}_{\text {sbulk }}$ (grid specific values). For detail see [12]. The median of HCB concentration in air from background side (Kosetice) was used. The evaluation was performed in MATLAB.

\section{Results and Conclusions}

Concentration maps of DDT and HCB were constructed with a high accuracy of prediction and their pools were computed (Fig. 2 and 3). Based on these results, the total POPs pool in soils was determined in grassland, forests soil and arable land (Fig. 4) 


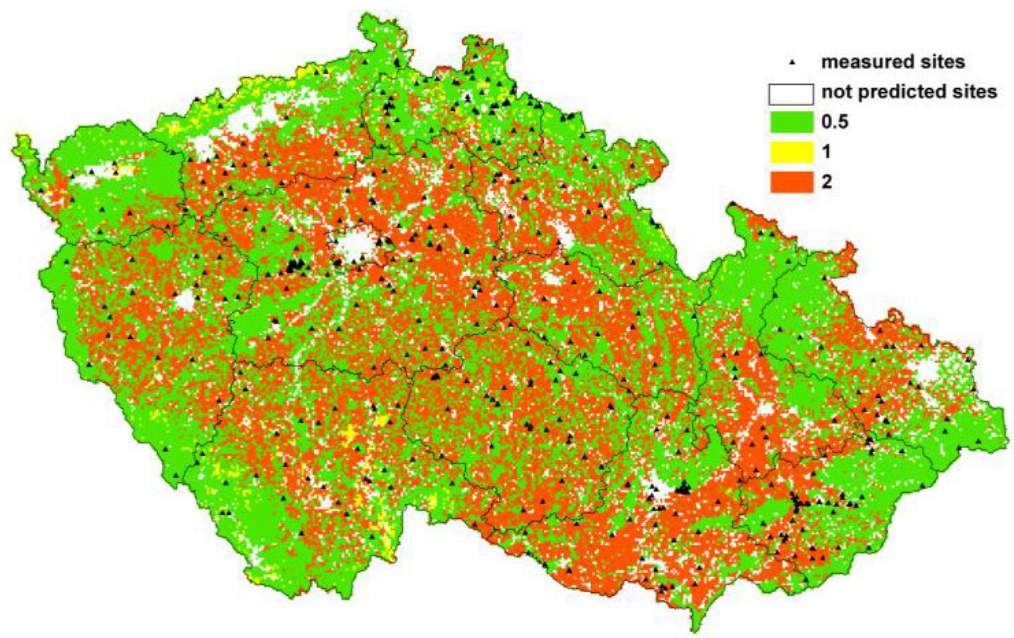

Fig. 2. Spatially resolved (grid of $1 \times 1 \mathrm{~km}$ ) pools of $\mathrm{HCB}\left(\mathrm{kg} \cdot \mathrm{km}^{-1}\right)$

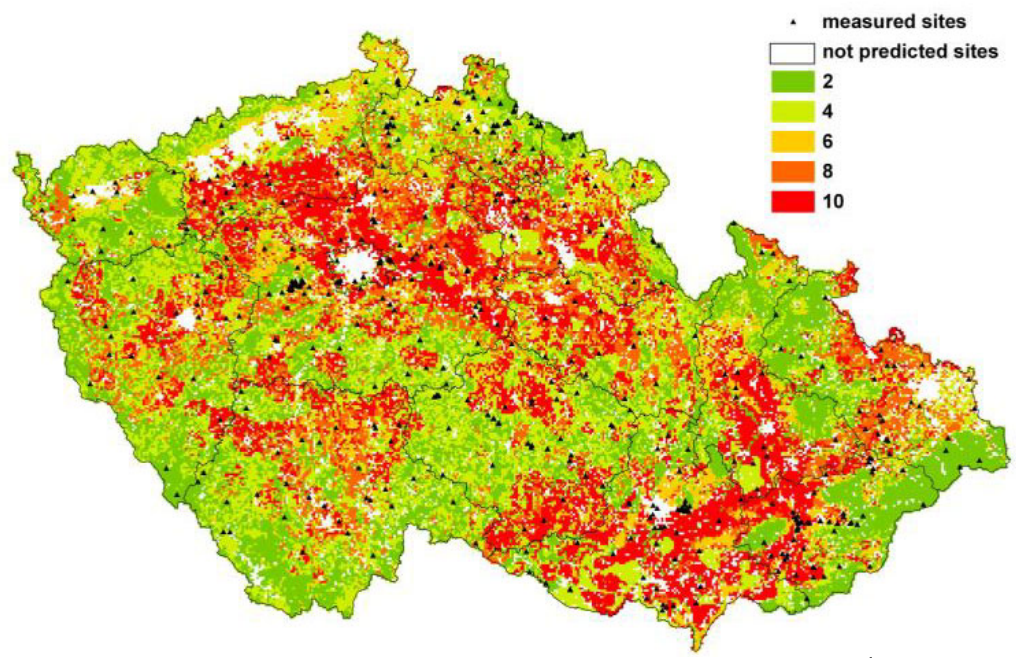

Fig. 3. Spatially resolved (grid of $1 \times 1 \mathrm{~km}$ ) pools of DDT $\left(\mathrm{kg} \cdot \mathrm{km}^{-1}\right)$

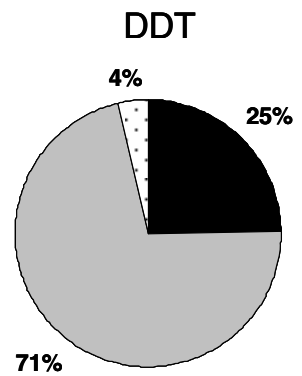

HCB

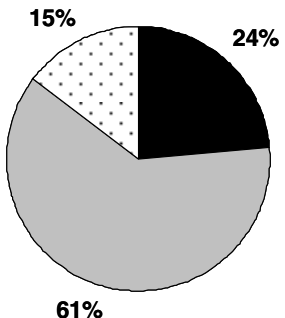

- Forest soil

$\square$ Agriculture soil

$\square$ Grassland

Fig. 4. Percentage of the total DDT and HCB pool in grassland, forests soil and arable land 
HCB and DDT maps clearly show higher pools in lowlands when compared to mountain soils. It is a result of using these compounds as pesticides for several decades. Volatilization maps show that pools are active source of these pollutants during warm part of year. This is in contrast to colder regions in mountains which are target places of air transport e.g. cold condensation nearly during whole year (Fig. 5 and 6).

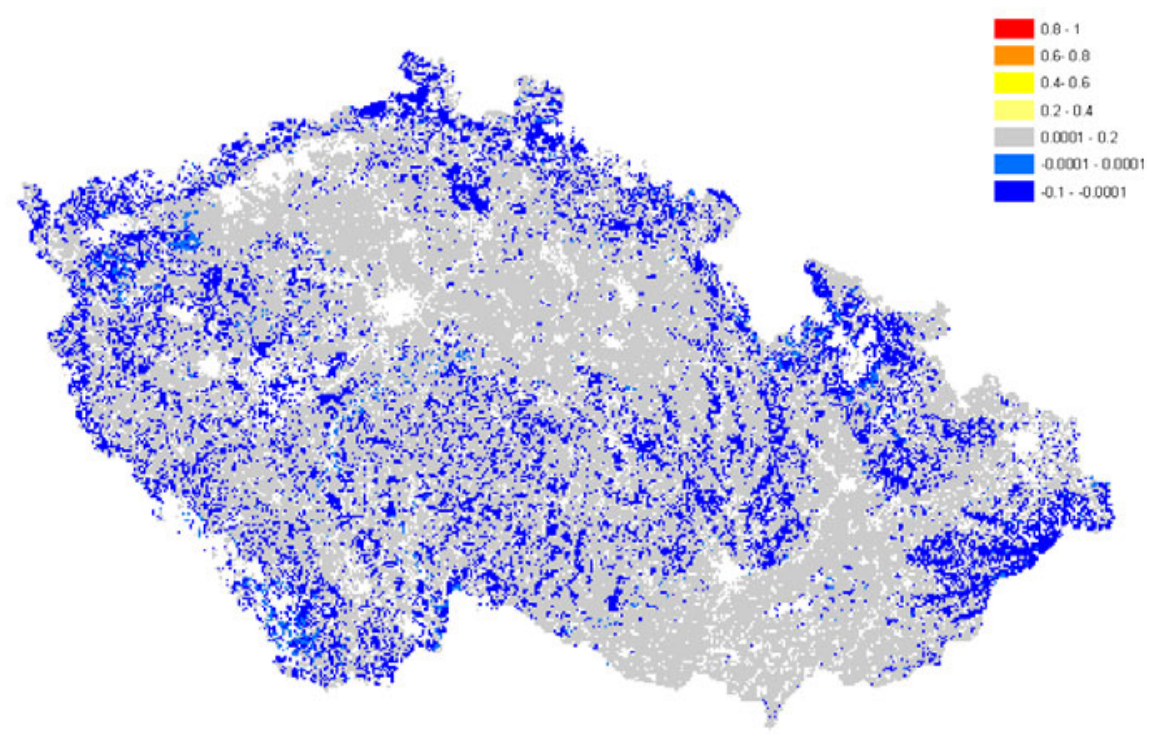

Fig. 5. Volatilization flux of HCB from soil in January $\left(\mathrm{ng} \cdot \mathrm{m}^{-2} \cdot \mathrm{h}^{-1}\right)$

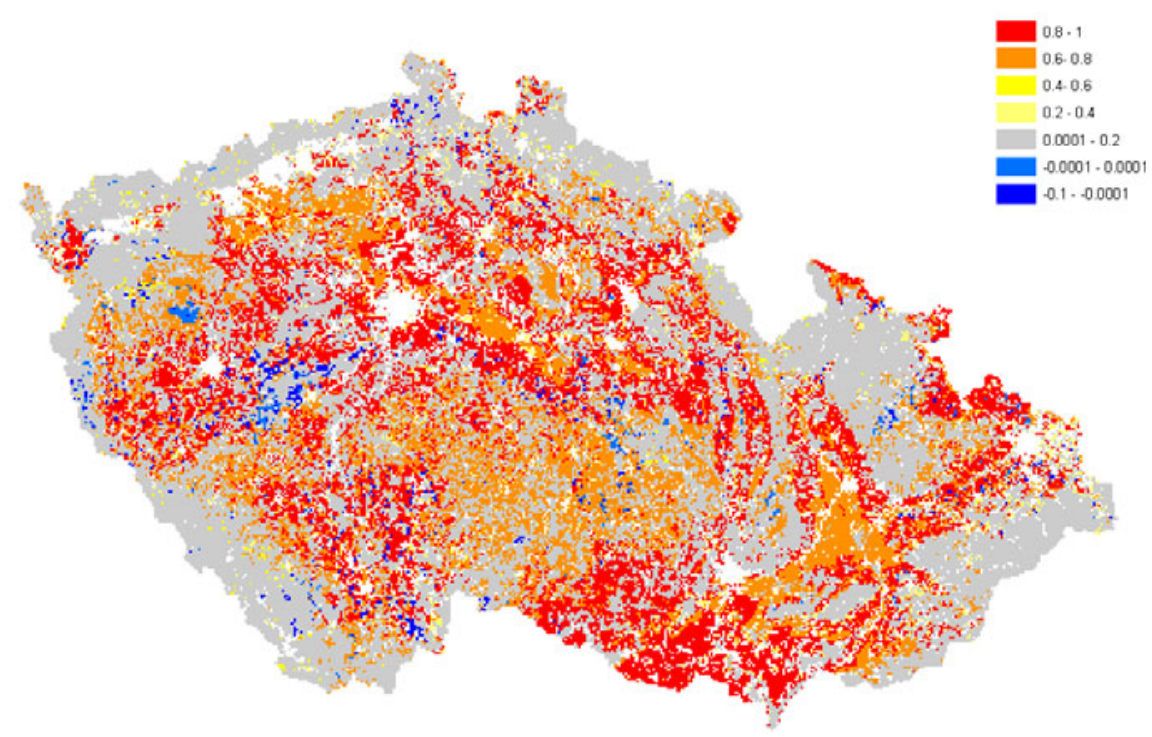

Fig. 6. Volatilization flux of HCB from soil in July $\left(\mathrm{ng} \cdot \mathrm{m}^{-2} \cdot \mathrm{h}^{-1}\right)$ 
This approach was proved to be very suitable. The total amount of a substance volatilized into air was determined. The areas with a high potential for deposition and volatilization and areas with potential for fast pesticides concentration changes in soil were identified during the analysis. Maps have been visualized on the web portal GENASIS (Global Environmental Assessment Information System) to provide information on environment contamination.

Acknowledgments. The research was supported by CETOCOEN (CZ.1.05/2.1.00/ 01.0001) project, granted by the European Union and administered by the Ministry of Education, Youth and Sports of the Czech Republic (MEYS), by MEYS (MSMT0021622412).

\section{References}

1. Bailey, R.E.: Global hexachlorobenzene emissions. Chemosphere 43, 167-182 (2001)

2. Denier van der Gon, H., van het Bolscher, M., Visschedijk, A., Zandveld, P.: Emissions of POPs and eight candidate POPs from UNECE-Europe in 2000, 2010 and 2020 and the emission reduction resulting from the implementation of the UNECE POP protocol. Atmos. Environ. 41, 9245-9261 (2007)

3. Holoubek, I.: Úvodní národní inventura persistentních organických polutantů v České republice. Project GF/CEH/01/003: Enabling activites to facilitate early action on the implementation of the Stockholm convention on persistent organic pollutants (POPs) in the Czech Republic. TOCOEN Report No. 249, Brno (2005)

4. Barber, J.L., Sweetman, A.J., Wijk, D.W., Jones, K.C.: Hexachlorbenzene in the global environment: Emissions, levels, distribution, trends and processes. Sci. Tot. Environ. 349, 1-44 (2005)

5. Bossard, M., Feranec, J., Otahel, J.: CORINE land cover technical guide- Addendum 2000, Technical report No 40 European Environment Agency, Copenhagen (2000)

6. Breiman, L.: Random forests. Machine Learning J. 45, 5-32 (2001)

7. Breiman, L., Friedman, J., Stone, C.J., Olshen, R.A.: Classification and Regression Trees. Chapman and Hall, New York (1984)

8. Kubosova, K., Komprda, J., Jarkovsky, J., Sanka, M., Hajek, O., Dusek, L., Holoubek, I., Klanova, J.: Spatially resolved distribution models of POP moncentrations in moil: A stochastic approach using regression trees. Environ. Sci. Technol. 43, 9230-9236 (2009)

9. Cupr, P., Bartos, T., Sanka, M., Klanova, J., Mikes, O., Holoubek, I.: Soil burdens of persistent organic pollutants - Their levels, fate and risks Part III. Quantification of the soil burdens and related health risks in the Czech Republic. Sci. Tot. Environ. 408, 486$494(2010)$

10. Mackay, D.: Multimedia Environmental Models: The Fugacity Approach, 2nd edn. Lewis Publishers, Boca Raton (2001)

11. Komprda, J., Kubosova, K., Dvorska, A., Scheringer, M., Klanova, J., Holoubek, I.: Application of an unsteady state environmental distribution model to a decadal time series of PAH concentrations in Central Europe. J. Env. Monit. 11, 269-276 (2009)

12. Koblizkova, M., Ruzickova, P., Cupr, P., Komprda, J., Holoubek, I., Klanova, J.: Soil Burdens of Persistent Organic Pollutants: Their Levels, Fate, and Risks. Part IV. Quantification of Volatilization Fluxes of Organochlorine Pesticides and Polychlorinated Biphenyls from Contaminated Soil Surfaces. Environ. Sci. Technol. 43, 10-18 (2009) 